\title{
Desenvolvimento do turismo baseado em elementos culturais
}

\section{Tourism development based on cultural elements}

\author{
Irene Camilo* $\mathrm{e}$ \\ Miguel Bahl**
}

\begin{abstract}
RESUMO - Neste $\operatorname{artigo~}^{1}$ são feitas considerações relacionadas ao desenvolvimento da atividade turística de forma sustentável e sobre patrimônio histórico cultural, como parte relevante para o incremento do turismo e fonte de sustentabilidade para a atividade. Trata também da importância do planejamento para minimizar os efeitos negativos causados pelo turismo desordenado no meio ambiente natural e antrópico. Aborda a importância do planejamento para a sustentabilidade dos destinos turísticos, bem como a valorização do patrimônio como reforço da identidade de um determinado espaço geográfico. A metodologia utilizada foi a de pesquisa bibliográfica. A fundamentação embasou-se em autores que abordam os assuntos referentes ao planejamento sustentável, patrimônio histórico cultural e identidade.
\end{abstract}

Palavras-chave: Turismo sustentável; Patrimônio histórico cultural; Identidade cultural.

ABSTRACT - In this article are made considerations related to the development of tourism in a sustainable way and on cultural heritage as part relevant to the increase in tourism and source of sustainability for the activity. This also of the importance of planning to minimize the negative effects caused by tourism disorderly environment in natural and man-made. It addresses the importance of planning for the sustainability of tourist destinations, and the recovery of assets and strengthening the identity of a particular geographical area. The methodology used was to literature search. The theory was used by authors that in dealing with matters relating to sustainable planning, heritage and cultural identity.

Key words: Tourism development; Historical cultural heritage; Cultural identity.

\footnotetext{
* Formação: Graduação em Turismo pela Universidade Federal do Paraná (UFPR); Especialização em Administração Universitária (UFPR) e em Educação Ambiental pelo Instituto Brasileiro de PósGraduação e Extensão (IBPEX); Mestrado em Teoria Literária pelo Centro Universitário Campos de Andrade (UNIANDRADE). Experiência na área de Turismo, atuando principalmente nos seguintes temas: desenvolvimento, hotelaria, eventos. Disciplinas ministradas: Metodologia Científica, Logística e Transportes, Roteiros Turísticos, Turismo e Qualidade, Segmentação de Mercado e Formatação de Produtos Turísticos. E-mail: irenecamilo2311@gmail.com

** Formação: Graduação em Turismo e Licenciaturas em Geografia e em Estudos Sociais pela Universidade Federal do Paraná (UFPR). Mestrado e Doutorado em Turismo em Ciências da Comunicação pela Universidade de São Paulo (USP). Estágio pós-doutoral desenvolvido na Universidade de Girona (Espanha). Atividade profissional: Professor do Departamento de Turismo da UFPR junto ao curso de Graduação em Turismo e aos Programas de Mestrado em Turismo e Mestrado e Doutorado em Geografia. Editor da Revista Turismo e Sociedade. E-mail: migbahl@ufpr.br

${ }^{1}$ A versão preliminar deste artigo foi apresentada no X SIT - Seminário Internacional de Turismo realizado na cidade de Curitiba em 2008, tendo recebido Menção honrosa atribuída pelas avaliações da Comissão Científica (Trabalho de pós-graduação).
} 


\section{INTRODUÇÃO}

O turismo tornou-se um dos veículos mais importantes para o intercâmbio cultural, seu planejamento deve proporcionar oportunidades responsáveis e bem geridas aos integrantes das comunidades receptoras, assim como deve proporcionar aos turistas a experimentação e a compreensão da cultura e do patrimônio de uma localidade.

Os fundamentos do desenvolvimento turístico devem pautar-se por critérios de sustentabilidade, considerando a questão ecológica em longo prazo, a viabilidade econômica e o equilíbrio ético social e ambiental para as comunidades receptoras.

A partir destes enunciados iniciais elaborou-se este artigo que está basicamente dividido em duas partes.

$\mathrm{Na}$ primeira parte são tecidas algumas considerações relacionadas ao desenvolvimento da atividade turística de forma sustentável. São feitas algumas reflexões sobre o planejamento do turismo, como ferramenta para minimizar os efeitos negativos causados pela sua ocorrência desordenada no meio ambiente natural e antrópico. Evidencia-se a importância do planejamento para a sustentabilidade dos destinos turísticos.

$\mathrm{Na}$ segunda parte, considera-se o patrimônio histórico cultural como parte relevante para o incremento do turismo e fonte de sustentabilidade para a atividade. Pretendeu-se desta forma discutir a importância do patrimônio como expressão de cultura e de identidade. Entendeu-se o espaço ocupado pelo patrimônio cultural material e imaterial - como o território no qual determinada comunidade reivindica a sua identidade cultural. Destaca-se sobre o planejamento para a sustentabilidade dos destinos turísticos, bem como a valorização do patrimônio como reforço da identidade.

A metodologia utilizada foi a de pesquisa bibliográfica, embasada em autores que contemplassem os assuntos pertinentes a planejamento turístico, patrimônio histórico cultural e identidade.

\section{PLANEJAMENTO SUSTENTÁVEL DO TURISMO}

A expansão da atividade turística repercute no ambiente, na vida econômica, social e cultural das áreas receptoras, e gera impactos quantitativos e qualitativos no 
ambiente em que se desenvolve. Desta forma tem figurado como tema prioritário na pauta de discussões dos planejadores, acadêmicos e gestores de políticas públicas, interessados na temática.

De acordo com Molina e Rodriguez (2001, p. 57):

Na América Latina a necessidade de planejar tem estado latente há muitos anos. [...] não obstante seu atraso e pobreza, os países da América Latina têm aceitado a viabilidade da mudança em suas estruturas políticas, sociais e econômicas mediante o planejamento.

Os autores afirmam que devido a fatores sociais a América Latina, como um todo se encontra disposta a realizar mudanças através do planejamento, entre eles os relacionados ao turismo. Segundo Dias (2003), mesmo o turismo sendo considerado como uma das principais atividades econômicas mundiais, apenas recentemente está sendo visto como peça fundamental no processo de desenvolvimento e que está:

\footnotetext{
Cada vez mais se incorporando como um componente da qualidade de vida do ser humano, atividade essencial de aproximação dos povos e de superação de barreiras raciais e étnicas existentes. No entanto, em que pesem os importantes aspectos positivos do desenvolvimento turístico, há problemas que devem ser contornados e que podem trazer graves conseqüências para qualquer localidade, e que só poderão ser evitados com o rigoroso planejamento da atividade [...]. (DIAS, 2003, p. 13).
}

Para o autor as consequências da atividade podem ser evitadas através do seu planejamento. Como Molina e Rodriguez colocam que a América Latina está disposta a realizar mudanças para sair da situação social que vive atualmente, e sendo o turismo uma atividade geradora de renda, os autores ainda destacam o fato de que a atividade será positiva caso o planejamento seja seguido rigorosamente.

Considerando o crescimento acelerado da atividade em muitos países, o turismo vem se apresentando como a mais importante fonte de renda, constituindo-se, em potencial, como forte aliado no combate à pobreza. Entretanto, independentemente dos efeitos positivos, advindos do turismo, na economia de muitas nações, os problemas socioambientais e os efeitos negativos nas culturas das comunidades receptoras se ampliam, comprometendo a qualidade de vida e do ambiente. 
A falta de planejamento e gestão sustentáveis das áreas turísticas pode fazer da visita a elas uma aventura, colocando a conservação de importantes patrimônios em risco.

Para Ruschmann (1997), os danos ambientais, decorrentes do desenvolvimento descontrolado da atividade turística provocam a poluição do ar, da água e sonora. $\mathrm{O}$ comportamento inadequado dos turistas - pisoteio; coleta de frutas, plantas e flores; vandalismo; incêndios etc. - pode contribuir efetivamente para o desaparecimento de várias espécies de animais e plantas; degradação da paisagem, de sítios históricos e de monumentos. O excesso de pessoas em sítios históricos ou naturais resulta na sua degradação, inclusive pela ação de grafiteiros e de furtos de peças. A concentração massiva de turistas no tempo e no espaço congestiona praias, cidades e rodovias modificando o modo de vida de uma comunidade.

Para evitar esses conflitos evidencia-se a necessidade de realizar campanhas e programas de educação ambiental, tanto para crianças e adultos, enquanto turistas e moradores das localidades receptoras.

Segundo Frangialli (1999), à medida que se procede a um adequado desenvolvimento do turismo, este poderá reduzir ao mínimo seus efeitos negativos para o meio ambiente e aumentar consideravelmente seus efeitos benéficos.

Nesta perspectiva aponta-se para o paradigma da sustentabilidade que, aplicado ao turismo, assume a dimensão de que o desenvolvimento turístico deverá fundamentarse em critérios de sustentabilidade, ou seja, "há de ser suportável ecologicamente em longo prazo, viável economicamente e equitativo desde uma perspectiva ética e social para as comunidades locais [...]”. (CARTA DE LANZAROTE, citada por CAPECE, $1997)^{2}$.

Sendo o turismo um importante instrumento para propiciar desenvolvimento, pode e deve participar ativamente na estratégia do desenvolvimento sustentável. A gestão do turismo deve garantir a sustentabilidade dos recursos naturais e culturais dos quais depende.

O desenvolvimento sustentável é entendido pela Comissão Mundial sobre Meio Ambiente e Desenvolvimento - CMMAD como:

\footnotetext{
${ }^{2}$ Conferencia Mundial de Turismo Sostenible. Lanzarote, Islas Canarias, España. Del 27 al 28 de abril de 1995.
} 
Um processo de transformação, no qual a exploração dos recursos, a direção dos investimentos, a orientação da evolução tecnológica e a mudança institucional se harmonizam e reforçam o potencial presente e futuro, a fim de atender às necessidades e aspirações humanas. (CMMAD 1991, p. 49 apud RUSCHMANN, 1997) ${ }^{3}$.

Evidencia-se, assim, em todo o mundo a premente necessidade do planejamento e da gestão das atividades turísticas sob as premissas da sustentabilidade ${ }^{4}$. A sustentabilidade social e cultural assegura que o desenvolvimento aumente o controle das pessoas sobre suas vidas e fortaleça a identidade de uma comunidade.

Embora se possa considerar que as ideias contidas no turismo sustentável ainda estejam em processo de construção, seja no aspecto teórico-conceitual, seja no aspecto das estratégias e ações implementadas, existe uma consciência crescente da importância de pensar e agir em prol do turismo sustentável, com vistas a minimizar os efeitos negativos e maximizar aqueles que apontem para os caminhos da conservação do meio ambiente e da justiça social.

\begin{abstract}
O turismo, sob as bases da 'sustentabilidade', apresenta maior potencial para a maximização dos benefícios, sejam eles econômicos, sociais ou ambientais. É capaz de promover a qualidade de vida das populações locais, oferecer maior qualidade das experiências turísticas ao visitante e levar à proteção do ambiente visitado, garantindo a manutenção do patrimônio ambiental para as comunidades locais e visitantes que dele dependem intimamente (ORGANIZAÇÃO MUNDIAL DO TURISMO, 2003).
\end{abstract}

Embora as recomendações da Organização Mundial do Turismo estejam presentes nas políticas públicas, o que se verifica na prática é que ainda existem muitos problemas ambientais, outros de ordem social e cultural nas comunidades receptoras. $\mathrm{Na}$ realidade, não são muito numerosos os estudos no mundo e no Brasil que se destinam a avaliar os impactos causados pelo turismo. Constata-se, entretanto, que em alguns países a atividade vem trazendo efeitos economicamente positivos em áreas que apresentam relevantes patrimônios naturais e culturais.

\footnotetext{
3 COMISSÃO MUNDIAL SOBRE MEIO AMBIENTE E DESENVOLVIMENTO. "Nosso Futuro Comum”. 2. ed. Rio de Janeiro: FGV, 1991.

${ }^{4}$ A ampliação do conceito de desenvolvimento sustentável envolve, na atualidade, diferentes dimensões: ambiental, social e econômica que se combinam e se complementam.
} 


\title{
3 PATRIMÔNIO CULTURAL E O TURISMO
}

Pode-se afirmar que o patrimônio cultural deva ser compreendido como mais um recurso à disposição das comunidades para seu desenvolvimento. Essa concepção de patrimônio como recurso econômico, capaz de gerar emprego e renda, está associada ao crescimento do turismo, e à necessidade das pessoas em conhecerem cada vez mais a diversidade cultural das regiões, dos territórios nacionais e de todo o planeta.

De acordo com Neves (2003, p. 56):

\begin{abstract}
A questão da preservação do patrimônio cultural, entretanto, está longe de ser facilmente equacionada. Mesmo se tratando do patrimônio de "pedra e cal", ou seja, o edificado é importante lembrar que também aí existem relações conflituosas. Há interesse por parte da especulação imobiliária que, no afã da lucratividade capitalista e informada pela concepção e uma modernização selvagem, enxerga nesses bens um obstáculo, para a ampliação de suas transações comerciais.
\end{abstract}

A autora afirma que devido à modernização e o anseio pela lucratividade imediata, as edificações que poderiam tornar-se espaço de cultura e lazer, acabam servindo basicamente aos interesses particulares.

O crescimento contínuo e desordenado das cidades, a especulação imobiliária, as mudanças dos comportamentos, os novos valores e estilos de vida podem gerar impactos irreversíveis nos patrimônios, pois são fatores resultantes da vida capitalista da sociedade globalizada.

Margarita Barretto (1999) discute sobre as transgressões dos espaços públicos, o mau trato dos lugares, a privatização das ruas, a insegurança urbana, geralmente impulsionada pelo aumento dos índices de violência e o desprezo do poder público e privado em relação ao patrimônio. O desejo da convivência cultural, do lazer, do ideal da revitalização dos bens culturais esbarra nas transgressões urbanas. Portanto, vive-se um momento crucial. De um lado a preocupação com a violência que isola o homem nos apartamentos, nos condomínios e nos shopping-centers ou nos muros que isolam as casas, de outro, a busca pelo conhecimento cultural, o sentimento de que é necessário reviver tradições e interagir com outras culturas. Para Barretto a resposta para a transgressão do espaço público e coletivo "parece estar no repensar os grandes 
conglomerados urbanos, partindo, de um planejamento que tome em conta as necessidades humanas" (BARRETTO, 1999, p. 41).

Para a autora os usuários se comportam de duas maneiras em relação ao uso do espaço público: privatização do espaço ou uso equivocado desse espaço, sujando-o e até depredando-o. A partir disso, pode-se observar que não é difícil constatar uma crescente privatização das ruas, pela classe média, que fecha entradas aos bairros, assim como praias, com a justificativa da segurança.

Os ensaios de Roberto da Matta (1991) parecem sugerir que a dicotomia entre a casa e a rua é uma particularidade da sociedade brasileira. Haveria uma oposição histórica entre a casa e a rua que faz com que esta última seja considerada um espaço desprezível e, por conseguinte, tudo o que está nela, não merece o cuidado que mereceria o bem que está dentro de casa.

Parece que no imaginário social brasileiro o conceito de "público" equivale ao "de ninguém".

“O espaço da rua é tão impessoal, tão de ninguém quanto a água de um rio que flui. Este espaço impessoal, temido, pode ser maltratado, pode-se nele jogar lixo, quebrar coisas". (BARRETTO, 1999, p. 41).

O Patrimônio cultural se tornou um dos principais elementos no processo de planejamento e ordenação da dinâmica de crescimento das cidades e como um dos itens estratégicos na afirmação de identidade de grupos e comunidades. (FONSECA, 1997).

É de grande importância que se obtenha a consciência de que o patrimônio cultural é um fator de desenvolvimento para a sociedade, sendo necessária uma gestão adequada para que os espaços culturais sejam usados de maneira a beneficiar uma comunidade receptora.

Em se tratando do uso dos elementos culturais pelo turismo, em Bahl (2004, p. 46-47), se encontra a proposição de algumas ações:

- Identificação de potencialidades, analisando-se e classificando a quantidade e qualidade dos atrativos;

- Estabelecimento de políticas e de incentivos à preservação;

- Realização de atividades que possibilitem o resgate da memória do local;

- Delimitação de áreas ou locais que contenham edificações ou elementos culturais e históricos mais expressivos; 
- Discriminação da destinação de uso e de reaproveitamento das edificações;

- Eleição e seleção de edificações a serem tombadas;

- Incentivo ou determinação de mecanismos que possibilitem a recuperação de edificações;

- Elaboração e proposição de itinerários para passeios e indicações de roteiros temáticos;

- Promoção e organização de eventos, exposições, mostras culturais, concursos de fotografias, entre outros tipos;

- Determinação e desenvolvimento de programas e projetos que promovam a revitalização de bairros, ruas, prédios;

- Estímulo à realização de encenações e atividades tradicionais;

- Efetivação de acervos e estruturação de museus interiores ou em parques e áreas abertas;

- Organização de parques com espaços temáticos, memoriais ou outras formas de representação física e material.

Tais ações devem estar pautadas em políticas públicas de incentivo e resgate da cultura de um local, que devem contemplar programas de conservação e uso adequado dos elementos culturais como atrativo turístico. Para que essas ações resultem em benefício para uma comunidade faz-se necessário a participação da mesma nas discussões, decisões e nos resultados econômicos, desenvolvendo projetos que promovam a revitalização de bairros, ruas e prédios.

Portanto, a revitalização indica a retomada das discussões sobre preservação, conservação e restauração do patrimônio e, essencialmente, a preocupação com espaços e manifestações que permitem o olhar, a convivência, o conhecimento e a interação com valores, histórias, símbolos e manifestações.

\footnotetext{
A noção de patrimônio atualmente não inclui apenas a herança de cada povo, as expressões "mortas" de sua cultura - sítios arqueológicos, arquitetura colonial, antigos objetos em desuso, mas também os bens culturais visíveis e invisíveis, como os novos artesanatos, línguas, conhecimentos, documentações e comunicação do que se considera apropriado através das indústrias culturais. (CANCLINI, 1994, p. 95).
}

Considera-se que o homem do século XXI busca o conforto da tecnologia e reconhece, cada vez mais, a necessidade de manutenção do patrimônio como elemento 
de identidade, de herança cultural, de referência sobre um passado que precisa estar vivo, para servir de equilíbrio perante a vida moderna.

Ulpiano Meneses (1999) discute de forma consistente a questão do uso da cultura. Coloca como temas para reflexão problemas como a cenarização das cidades, o fetichismo da cultura, o consumo do bem cultural, o desenraizamento dos turistas, ou seja, põe em debate o tipo de turismo que se pratica.

Américo Pelegrini Filho (1993) apresenta vários exemplos de patrimônios usados para fins culturais e que viabilizam a manutenção de heranças culturais, assim como, o consumo da própria cultura.

Para o autor, a revitalização do patrimônio, tem contribuído para o desenvolvimento dos lugares; quando as comunidades percebem que a riqueza da identidade representa um impulso à continuidade da herança cultural e a geração de emprego e renda por meio da atividade turística.

Sobre o binômio cultura e turismo, Gândara et al. (2006, p. 130), destacam que:

O Turismo é uma atividade que, além dos aspectos econômicos, desenvolve aspectos sócio-culturais de grande importância, utilizando dentro da sua dinâmica, processos culturais de muita relevância e abrangência. Estabelecendo, desta maneira, uma tênue relação entre as áreas de cultura e turismo, podemos dizer que esta relação ainda encontra-se bastante tímida em termos de parcerias de atuação e ações integradoras.

Para os autores a dinamização dos setores necessita de políticas que visem a inter-relação entre cultura e turismo que possibilite ações integradas na conformação do produto turístico de acordo com os princípios do desenvolvimento sustentável.

O turismo, além de importante instrumento de promoção social e de dinamização econômica, é também, e principalmente, uma atividade cultural.

De acordo com Neves (2003, p. 59):

Conhecer lugares, assistir à apresentação de manifestações artísticas, degustar pratos peculiares de cada região, compartilhar com nativos a experiência de uma feira local, é conhecer elementos que dizem respeito a pessoas e suas sensibilidades, suas normas e valores, suas emoções. É um exercício de se colocar por alguns momentos na condição do outro que experimenta cotidianamente aquilo que, aos turistas, é proporcionado fortuitamente. 
Para a autora o desejo do turista é apreender o outro. Se a cultura é um processo dinâmico, em que novos usos são dados aos produtos culturais, também o turismo participa desse processo.

O turismo tornou-se um dos veículos mais importantes para o intercâmbio cultural, seu planejamento deve proporcionar oportunidades responsáveis e bem geridas aos integrantes de uma comunidade receptora, assim como deve proporcionar aos turistas a experimentação e a compreensão da cultura e do patrimônio dessa comunidade.

A relação entre patrimônio e o turismo é dinâmica e deve gerir-se de modo sustentável para a atual e para as futuras gerações.

\section{CONSIDERAÇÕES FINAIS}

A atividade turística deve ser desenvolvida respeitando o patrimônio cultural, que deve ser preservado e transmitido às gerações futuras. Portanto, o uso do patrimônio como atrativo turístico necessita de um planejamento sustentável, onde os bens culturais sejam expostos aos turistas de uma forma que valorize a cultura de uma comunidade receptora e proporcione aos turistas o intercâmbio cultural.

Para amenizar os efeitos negativos da atividade turística com relação ao patrimônio cultural, deve-se proporcionar à comunidade a participação no processo de exposição de seu patrimônio, favorecendo assim um sentimento de orgulho pela sua cultura. Cabe aos órgãos competentes oferecer oficinas de sensibilização à comunidade quanto ao valor do patrimônio e sua importância, ressaltando os benefícios de protegêlos e conservá-los tanto para a visitação quanto para a própria comunidade. Essas oficinas ajudarão tanto na conservação quanto no fortalecimento da identidade cultural.

Já na parte comportamental tanto dos turistas quanto da comunidade autóctone, é comum identificar efeitos oriundos das atitudes de alguns "vândalos" no patrimônio como forma de deixar suas marcas: o coração entalhado na árvore, o "estive aqui" nos banheiros públicos, nos ônibus, nos museus, nos telefones. Estas são, sem dúvida, formas de "marcar território" na falta de outra maneira de se destacar na multidão. A solução pode advir ao se realizar campanhas educativas, associadas a multas e punições, 
contando com um sistema de vigilância permanente por parte das autoridades competentes, além da colaboração dos cidadãos conscientes que o patrimônio e o espaço público são bens comuns.

O Turismo cultural contribui para a geração de conhecimento, de formação para os cidadãos e fundamentalmente para o desenvolvimento sustentável da atividade turística. Daí a importância do envolvimento das comunidades em sua conservação, como forma de oferecer um patrimônio o mais próximo possível de sua identidade, aos visitantes.

\section{REFERÊNCIAS}

BAHL, M. Fatores ponderáveis no turismo: sociais, culturais e políticos. Curitiba: Protexto, 2004.

BARRETTO, M. Espaço Público: usos e abusos. In: YÁZIGI, E., CARLOS, A. F. A., CRUZ, R. de C. A. da. Turismo: espaço, paisagem e cultura. São Paulo: Hucitec, 1999.

CANCLINI, N. G. O patrimônio cultural e a construção imaginária do nacional. Revista do Patrimônio Artístico Nacional, 23, p. 95-115, 1994.

CAPECE, G. R. Turismo sostenido y sustentable: una visión holística. Patagonia: El Bolsón, 1997.

DA MATTA, R. A casa e a rua: espaço, cidadania, mulher e morte no Brasil. Rio de Janeiro: Guanabara Koogan, 1991.

DIAS R. Planejamento do Turismo: política e desenvolvimento do turismo no Brasil. São Paulo: Atlas, 2003.

FONSECA. M. C. L. O patrimônio em processo: trajetória da política federal de preservação no Brasil. Rio de Janeiro: Ed. UFRJ, IPHN, 1997.

FRANGIALLI, F. Discurso de mensagem. In: Consideraciones sobre el turismo internacional: discursos e documentos. Madrid: WTO, 1999.

GÂNDARA, J. M. G.; CAMPOS, C. J. de; CAMARGO, L. A. R.; BRUNELII, L. H. Viabilizando a relação entre cultura e o turismo: diretrizes para o estabelecimento de políticas integradas entre os dois setores. Turismo - Visão e Ação, Itajaí, v. 8, n. 1, p. 129-140, jan./abr. 2006. 
MENESES, U. T. B. de. Os "usos culturais" da cultura. Contribuição para uma abordagem crítica das práticas e políticas culturais. In: YÁZIGI, E., CARLOS, A. F. A.; CRUZ, R. de C. A. da. Turismo: espaço, paisagem e cultura. São Paulo: Hucitec, 1999.

MOLINA S.; RODRIGUEZ S. Planejamento Integral do Turismo. Bauru: EDUSC, 2001.

NEVES, B. A. de C. Patrimônio Cultural e Identidade. In: MARTINS, J. C. O. (org.) Turismo, Cultura e identidade. São Paulo: Rocca, 2003.

Organização Mundial do Turismo - OMT. Turismo sustentável. São Paulo: Bookmann, 2003.

PELLEGRINI FILHO, A. Ecologia, cultura e turismo. Campinas: Papirus, 1993.

RUSCHMANN, D. Turismo e planejamento sustentável: a proteção do meio ambiente. Campinas: São Paulo, Papirus, 1997. 